\title{
A high-level cloud detection method utilizing the GOSAT TANSO-FTS water vapor saturated band
}

\author{
Nawo Eguchi ${ }^{1}$ and Yukio Yoshida ${ }^{2}$ \\ ${ }^{1}$ Research Institute for Applied Mechanics (RIAM), Kyushu University, Kasuga Park 6-1, Kasuga, Fukuoka, Japan \\ ${ }^{2}$ Center for Global Environmental Research (CGER), National Institute for Environmental Studies (NIES), \\ Onogawa 16-2, Tsukuba, Ibaraki, Japan
}

Correspondence: Nawo Eguchi (nawo@riam.kyushu-u.ac.jp)

Received: 18 April 2018 - Discussion started: 12 June 2018

Revised: 14 November 2018 - Accepted: 21 December 2018 - Published: 18 January 2019

\begin{abstract}
A detection method for high-level clouds, such as ice clouds, is developed using the water vapor saturated channels of the solar reflected spectrum observed by the Greenhouse gases Observing SATellite (GOSAT) Thermal And Near-infrared Sensor for carbon Observation Fourier Transform Spectrometer (TANSO-FTS). The clouds detected by this method are optically relatively thin (0.01 or less) and located at high altitude. Approximately $85 \%$ of the results from this method for clouds with cloud-top altitude above $5 \mathrm{~km}$ agree with the Cloud-Aerosol Lidar with Orthogonal Polarization (CALIOP) cloud classification. GOSAT has been operating since April 2009 with a 3-day repeat cycle for a pointwise geolocation pattern, providing a spectral data record that exceeds 9 years. Cloud information derived from GOSAT TANSO-FTS spectra could be powerful data for understanding the variability in cirrus cloud on temporal scales from synoptic to interannual.
\end{abstract}

\section{Introduction}

Cloud detection, especially for optically thin clouds at high altitudes, is important for enabling more accurate atmospheric trace gas retrievals from satellite remote sensing. Because cirrus cloud parameters have highly variable spatial and temporal scales, satellite observations for atmospheric trace gases require simultaneous cloud data over the same area. The cirrus cloud top altitude, which depends on tropopause height, was found to have a maximum of about $16 \mathrm{~km}$ in the tropics and to decrease with increasing latitude (about $10 \mathrm{~km}$ in the middle latitudes) (Nazaryan et al., 2008;
Sassen et al., 2008; Eguchi et al., 2007). The optical thickness of regularly observed cirrus clouds varies between 0.1 and 3.0 (Eguchi et al., 2007). Optically thin (optical thickness less than 0.1 ) and higher-level (above $8 \mathrm{~km}$ ) clouds are in general difficult to detect with conventional passive sensors that measure reflected sunlight (Holz et al., 2016). However, clouds with optical thickness less than 0.05 could be detected by the MODerate Resolution Imaging Spectroradiometer (MODIS) sensor (Dessler and Yang, 2003).

Some studies have used the water vapor saturated band to detect high-level clouds, such as cirrus clouds (Gao et al., 1993, 1998, 2002, 2004). The basic principle of the water vapor saturated band method is that the upward reflectance is less over lower-level clouds and cloud-free conditions because of the strong water vapor absorption in the band. On the other hand, large upward reflectance is observed when there are clouds in the upper troposphere because there is less water vapor above the high-level clouds (Gao et al., 1993). Therefore, the reflectance of the water vapor saturated band is used to detect upper tropospheric clouds. Gao et al. (2002) used the $1.38 \mu \mathrm{m}$ band of the MODIS to derive the reflectance of cirrus clouds globally.

The Greenhouse gases Observing SATellite (GOSAT) measures greenhouse gases over the globe using the Thermal And Near-infrared Sensor for carbon Observation (TANSO)Fourier Transform Spectrometer (FTS). The TANSO-Cloud and Aerosol Imager (TANSO-CAI) onboard the GOSAT is used to identify cloud and aerosol information (cloud and aerosol existence and properties, such as optical thickness and effective radius) within the TANSO-FTS instantaneous field of view (IFOV). The TANSO-CAI detects optically rel- 
atively thick clouds, as effectively as the MODIS on board the Terra and Aqua satellites (Ishida et al., 2011), but it has difficulty with optically thinner cirrus clouds (less than 0.1 optical thickness) because it does not have a strong water vapor absorption band and/or thermal infrared band that is effective for cirrus detection.

On the other hand, TANSO-FTS has both a strong water vapor absorption band (Band 3 of TANSO-FTS) and a thermal infrared band (Band 4). Since narrow-band spectrometry has been widely used for cloud detection, the cloud detection methods could be modified or updated for the high-resolution spectrum observed by the TANSO-FTS. Someya et al. (2016) have already refined the $\mathrm{CO}_{2}$ slicing method that utilizes TANSO-FTS thermal infrared spectral data. The water vapor saturated method used in the current GOSAT product is a single threshold test comparing a mean signal of the predefined 11 most $\mathrm{H}_{2} \mathrm{O}$-absorptive channels in the water vapor saturated band $\left(5150-5200 \mathrm{~cm}^{-1}\right)$ with the noise (Yoshida et al., 2011). Guerlet et al. (2013) used similar threshold tests and showed that the water vapor saturated band of GOSAT can detect thin cirrus clouds with the minimum of 0.02 optical thickness.

The aim of the present study is to develop a different method from the current water vapor saturated method using the typical spectral shape of the water vapor absorption band (Band 3) of TANSO-FTS constructed by the cluster analysis. The method is validated by comparison against the CloudAerosol Lidar and Infrared Pathfinder Satellite Observation (CALIPSO) on-board Cloud-Aerosol Lidar with Orthogonal Polarization (CALIOP) data. Section 2 describes the methodology of the high-level cloud detection method, Sect. 3 shows the results of the comparison study with CALIOP and Sect. 4 summarizes the results and gives our conclusions.

\section{Data and methodology}

This section describes the TANSO-FTS Level 1B (L1B) spectral data and CALIOP Level 2 cloud layer data, and the methodology for detecting scattering particles in the upper troposphere, such as high-level clouds.

\subsection{Analysis data}

\subsubsection{GOSAT observation overview and spectral information}

The polar orbiter GOSAT was launched on 23 January 2009 and has provided observations since April 2009 with a 3day revisit cycle. It carries two instruments, TANSO-FTS and TANSO-CAI. The present study uses TANSO-FTS L1B spectral data to detect high-level clouds for the ultimate purpose of reducing the error in retrieved trace gases, such as $\mathrm{XCO}_{2}$ and $\mathrm{XCH}_{4}$ (column-averaged dry air mole fractions of $\mathrm{CO}_{2}$ and $\mathrm{CH}_{4}$ ), which are also derived from the TANSO-
FTS spectral data. The GOSAT and its two instruments are described by Kuze et al. (2009, 2016).

The TANSO-FTS has four bands (Bands 1-4), comprising three narrow bands (Bands 1-3) in the SWIR region (12900$13200,5800-6400$, and $4800-5200 \mathrm{~cm}^{-1}$, respectively) and a wide TIR band (700-1800 $\mathrm{cm}^{-1}$; Band 4), and all except Band 1 are at a spectral resolution of $0.27 \mathrm{~cm}^{-1}$. Two polarization components of incident light (i.e., $P$ and $S$ polarization states) are measured separately for the three SWIR bands. The TANSO-FTS has two gain settings, high $(\mathrm{H})$ and middle (M), for SWIR bands. The M-gain is used over high reflectance surfaces (e.g., desert), and the H-gain elsewhere.

The IFOV of TANSO-FTS is $15.8 \mathrm{mrad}$, which corresponds to a nadir circular footprint of about $10.5 \mathrm{~km}$ in diameter at sea level. The acquisition time of each measurement is $4 \mathrm{~s}$. During nominal operation, three or five points along the cross-track direction are observed in sequence. The five-point mode was used when TANSO-FTS observation was started in April 2009, but as the stability of the pointing mechanism gradually degraded, the observation mode was changed to the three-point mode after August 2010. The TANSO-FTS also occasionally observes in targeted mode.

The high-level cloud detection method uses only Band 3P spectral data, because the signal-to-noise ratio (SNR) of Band $3 \mathrm{P}$ is larger than that of Band $3 \mathrm{~S}$ in most cases. Version 161.160 of the GOSAT TANSO-FTS L1B was used in this study.

\subsubsection{CALIPSO/CALIOP data}

The CALIOP Level 2 cloud layer product version 4.10 was used for this comparison analysis (Winker et al., 2007, 2010). The CALIOP instrument is on board CALIPSO, a polar orbiter with a 16-day revisit time. The CALIOP footprint (FOV) is approximately $100 \mathrm{~m}(130 \mu \mathrm{rad})$, observations are at about $333 \mathrm{~m}$ intervals (horizontal resolution) and the vertical resolution varies between 30 and $60 \mathrm{~m}$, depending on the altitude range. The present study used the $5 \mathrm{~km}$ integrated cloud layer product (footprint size $100 \mathrm{~m} \times 5 \mathrm{~km}$ ), which includes the altitudes of cloud top and bottom, and optical thickness. CALIOP can detect thin clouds with 0.01 optical thickness (e.g., McGill et al., 2007). On the other hand, the cloud-base altitude cannot be detected for optically thick clouds with optical thickness greater than approximately 4 .

We extracted cirrus cloud data derived from CALIOP from 1 January 2010 to 31 May 2013. Cirrus clouds were defined following Eguchi and Kodera (2010) as having a cloud top altitude above $5 \mathrm{~km}$ over latitudes above $30^{\circ}$ and above $8 \mathrm{~km}$ over latitudes below $30^{\circ}$.

\subsection{Detection of scattering particles in the upper troposphere}

Figure 1 shows a schematic of the detection of scattering particles at high altitudes (upper troposphere). The basic idea 


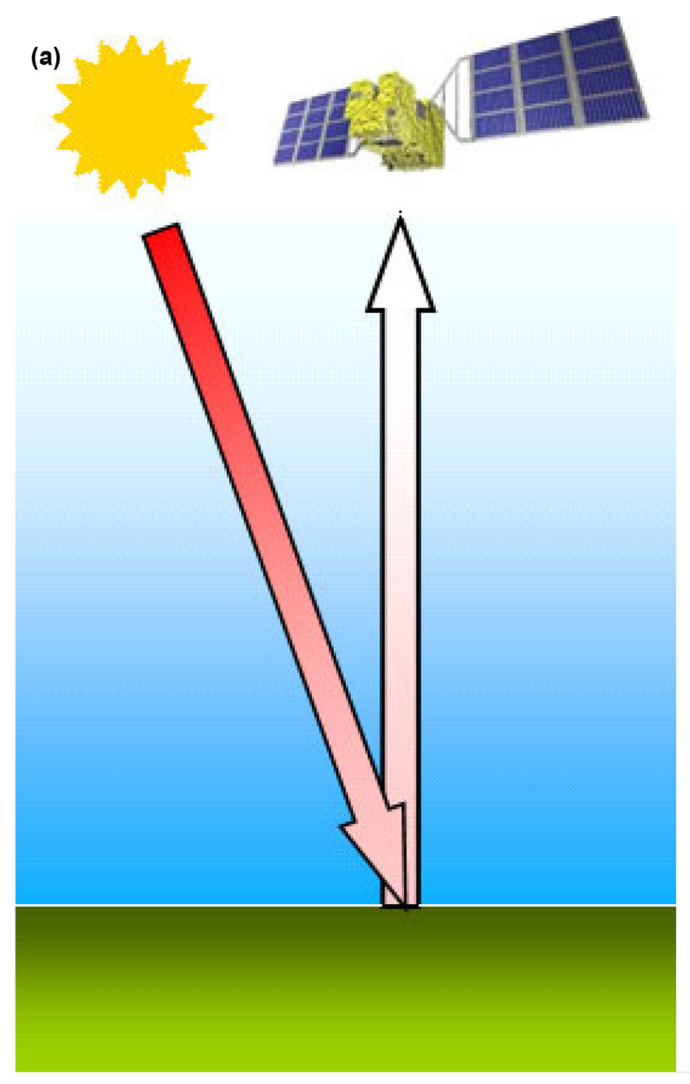

(c) Cloud-free case

(23 April 2009, path 05, scene 27, scan no. 10)

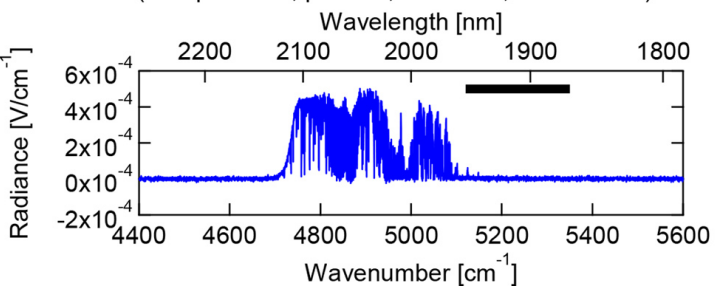

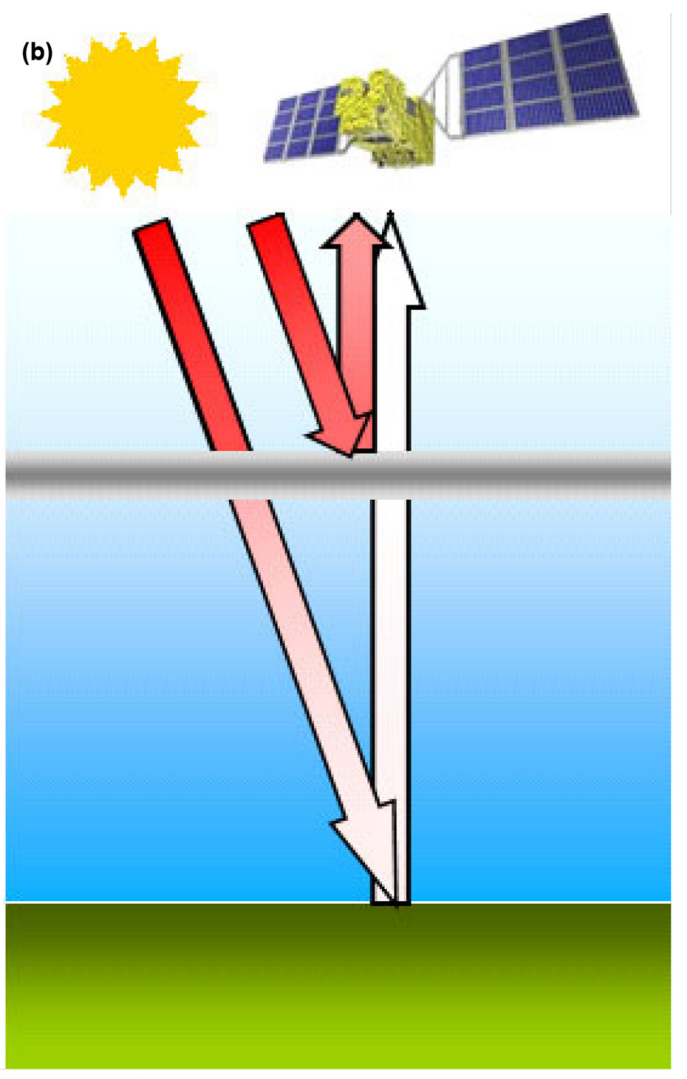

(d) High-level cloud case

(23 April 2009, path 05, scene 20, scan no. 16) Wavelength [nm]

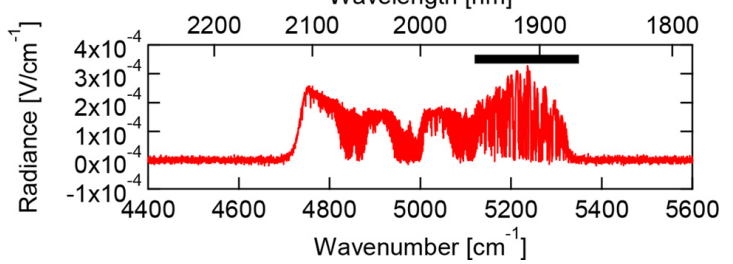

Figure 1. Panels (a, b) show schematics of the radiative transfer effects without (left) and with (right) scattering particles in the upper troposphere. The panels (c) and (d) show examples of the spectral shape of Band 3P without and with the scattering particles. The thick black line indicates the location of the water vapor absorption band focused in this study.

is from Gao et al. (1993, 2002). The principle is as follows: solar radiance in the saturated water vapor absorption band is completely absorbed by water vapor in the lower troposphere when scattering particles are absent in the upper troposphere. In contrast, a large amount of scattered solar radiance in this band reaches the top of the atmosphere when there are scattering particles in the upper troposphere. Therefore, high-level clouds can be detected by observing the level of upward radiance in the saturated water vapor absorption band. A saturated water vapor absorption band in the $5100-5300 \mathrm{~cm}^{-1}$ wavenumber region is covered by TANSOFTS Band 3. The lower panels in Fig. 1 show examples of TANSO-FTS Band 3P spectra with and without high-level cloud. As stated above, strong reflected radiance at the satu- rated water vapor absorption band is indicative for the highlevel cloud case.

Since atmospheric water vapor load is highly variable, surface reflected radiance might contaminate the signal under very dry conditions. To investigate the contribution of the surface reflected radiance, a radiative transfer simulation was conducted by using a line-by-line one-dimensional scalar radiative transfer model HSTAR (Nakajima and Tanaka, 1986). The absorption cross section of water vapor was calculated by the Line-By-Line Radiative Transfer Model (Clough et al., 2005). Figure 2a shows the simulated spectra for cloudfree cases with different precipitable water vapor amounts. Reflected radiance increases with decreasing precipitable water vapor amount, and the wavenumber region over which absorption remains saturated contracts. Figure $2 b$ shows the 
Table 1. Terms in the flowchart shown in Fig. 4.

\begin{tabular}{|c|c|}
\hline Terms & Description \\
\hline$S_{\mathrm{WV}}=\frac{\mathrm{AVSPC}_{\mathrm{WV}}}{\text { NOISE }}$ & Fraction of $\mathrm{AVSPC}_{\mathrm{wv}}$ wrt noise level \\
\hline$S_{\mathrm{ALL}}=\frac{\text { AVSPC }_{\text {total }}}{\text { NOISE }}$ & Fraction of $\mathrm{AVSPC}_{\text {total }}$ wrt noise level \\
\hline $\mathrm{AVSPC}_{\mathrm{wv}}=\operatorname{MEAN}\left(\mathrm{SPC}_{\mathrm{p}}\right)\left\{\begin{array}{l}5184.4 \leq \mathrm{wn} \leq 5185.4 \\
5188.6 \leq \mathrm{wn} \leq 5189.6 \\
5196.4 \leq \mathrm{wn} \leq 5197.8\end{array}\right.$ & Selected channels of Band 3P (wn means wavenumber) \\
\hline $\operatorname{AVSPC}_{\text {total }}=\operatorname{MEAN}\left(\mathrm{SPC}_{\mathrm{p}}\right)\{4400 \leq \mathrm{wn} \leq 5700$ & Averaged signal for the whole spectral region of Band 3P \\
\hline $\mathrm{NOISE}=0.5 \cdot\left(\mathrm{NOISE}_{\mathrm{L}}+\mathrm{NOISE}_{\mathrm{H}}\right)$ & Averaged noises outside Band3P \\
\hline NOISE $_{L}=\operatorname{STD}\left(\mathrm{SPC}_{\mathrm{p}}\right)\{4450 \leq \mathrm{wn} \leq 4600$ & Standard deviation of lower (left) wavenumber outside Band 3P \\
\hline NOISE $_{H}=\operatorname{STD}\left(\mathrm{SPC}_{\mathrm{p}}\right)\{5450 \leq \mathrm{wn} \leq 5650$ & Standard deviation of higher (right) wavenumber outside Band 3P \\
\hline
\end{tabular}

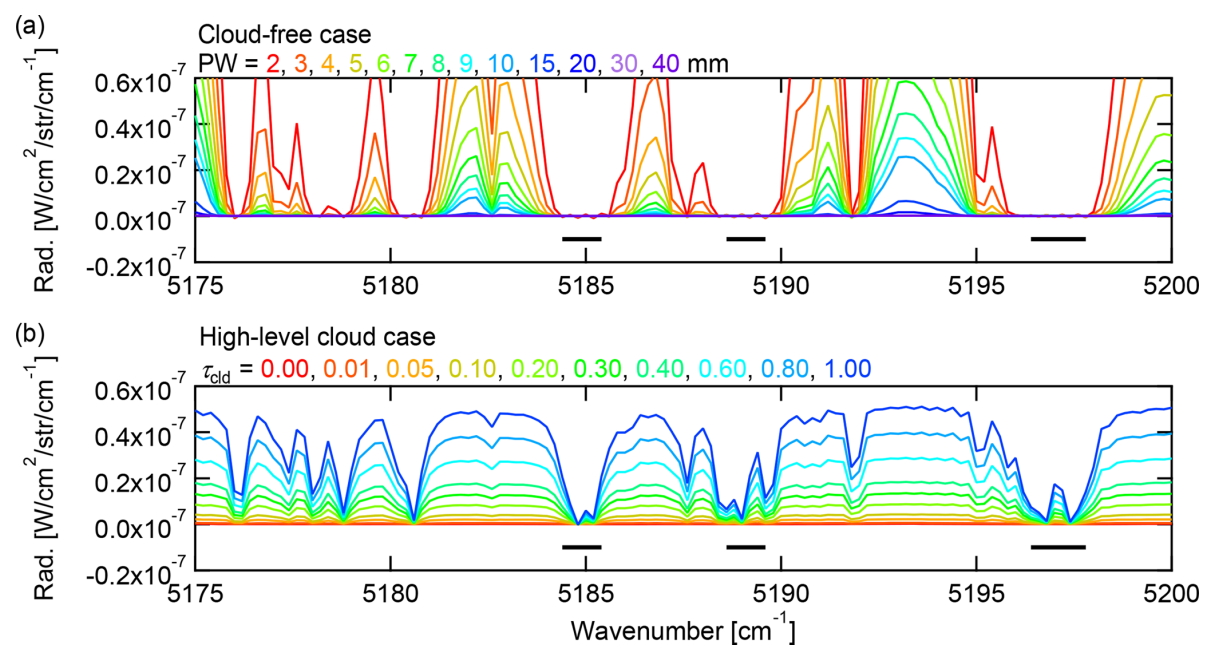

Figure 2. Simulated spectra for (a) cloud-free cases for different precipitable water vapor amounts and (b) high-level cloud cases for different cloud optical thicknesses. A Lambertian surface with albedo of 0.3 is assumed. Solar zenith angle and satellite zenith angle are set to 30 and $0^{\circ}$ (nadir viewing), respectively. The horizontal black bars show 5184.4-5185.4, 5188.6-5189.6 and 5196.4-5197.8 $\mathrm{cm}^{-1}$, respectively.

simulated spectra for the high-level cloud case for different cloud optical thicknesses. The spectral response patterns for these two cases are clearly different, so a wavenumber region that is sensitive to high-level cloud but insensitive to surface reflection can be determined.

A similar surface reflection issue was reported for the MODIS $1.38 \mu \mathrm{m}\left(7246.38 \mathrm{~cm}^{-1}\right)$ water vapor saturated band, and for the Visible Infrared Imager Radiometer Suite (VIIRS) the contribution of surface reflection is suppressed by narrowing the bandwidth (Hutchison et al., 2012). Since the spectral resolution of TANSO-FTS is higher than that of VIIRS, a more suitable set of channels can be selected. By taking the small spectral shift due to the gradual optical alignment change (Kuze et al., 2012) into account, three narrow windows (thick black lines in Fig. 2) are selected for highlevel cloud detection for the present study. Figure 2 also indicates that the spectral shape appears to provide additional useful information for the detection of high-level cloud.
To obtain typical spectral shapes for Band 3P, $k$ means clustering (MacQueen, 1965) was applied to a sample of Band 3P spectra that was normalized so that the area under the curve is unity. More than 12000 scenes obtained from 20 to 22 March 2010 under the condition of the solar zenith angle less than $70^{\circ}$ and SNR larger than 5 were clustered into 12 groups. Figure 3 shows the mean spectral shape of each group. The number of each group is given in descending order of the median brightness temperature in the $10 \mu \mathrm{m}$ window calculated from TANSO-FTS Band 4; i.e., Group 1 has the highest brightness temperature and probably corresponds to a scene without high-level cloud, and Group 12 has the lowest brightness temperature and corresponds to a scene with optically thick high-level cloud. Utilizing these mean spectral shapes as supervised data, a flowchart of the high-level cloud detection method is given in Fig. 4. Each step is explained below and the terms used in the flowchart are described in Table 1. 

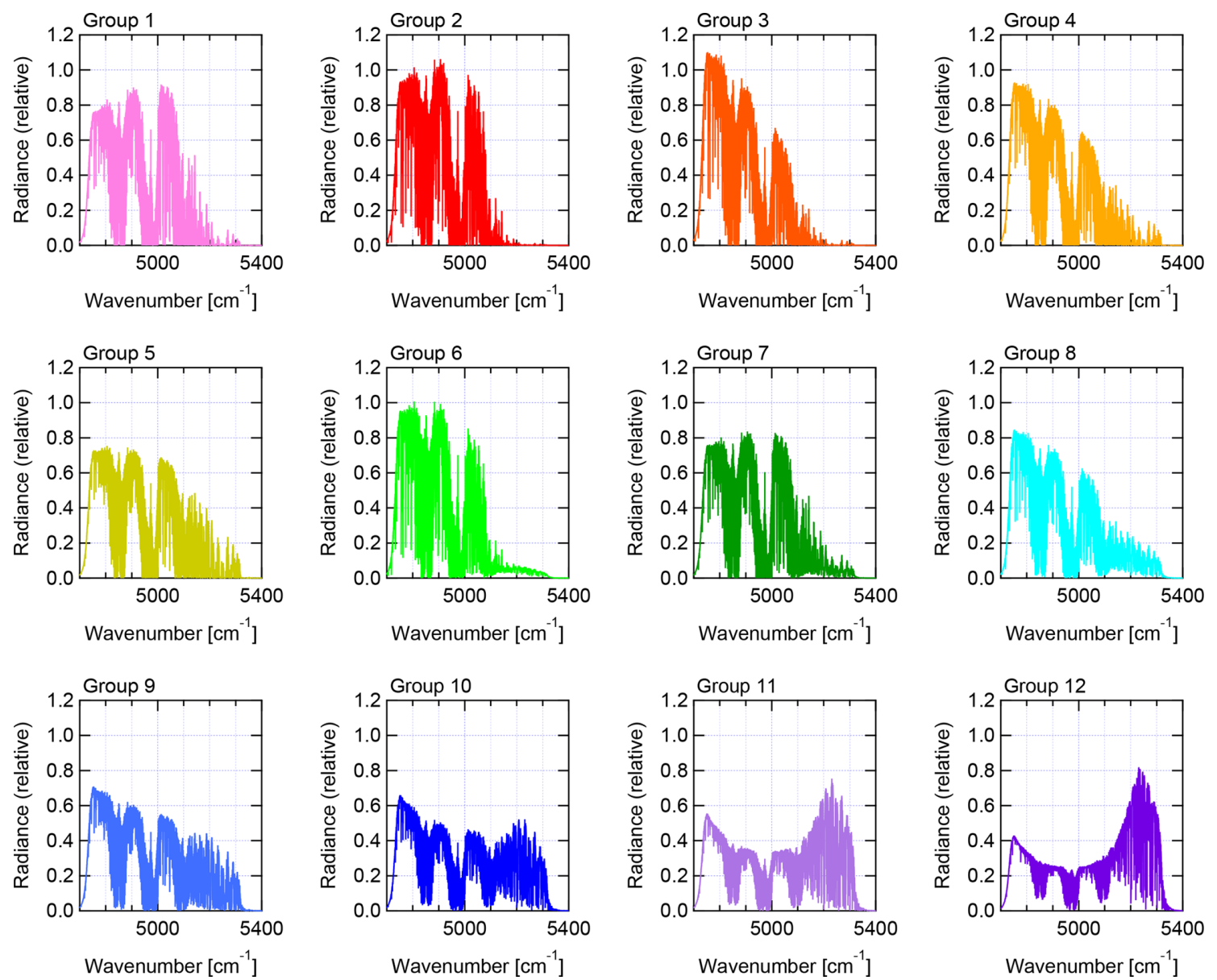

Figure 3. The 12 spectral groups of Band 3P spectra derived using $k$ means clustering. The groups from 1 to 12 were ordered from top left to bottom right.

We first checked the quality of the spectral data (Band 3P) to avoid anomalous spectral data. Since TANSO-FTS should point to the same location during the acquisition of an interferogram, data with an unstable viewing vector during the acquisition are treated as "poor quality data". When the interferogram is missing or saturated, or has spike noise, the corresponding spectral data are treated as "poor quality data". Distorted spectral data are detected by checking the average and standard deviation of the measured spectrum in the out of bandpass range. If these values deviate considerably from their nominal range, the data are treated as "poor quality data". Furthermore, we used data with solar zenith angle less than $90^{\circ}$ to avoid night-side data.

Next, the Band 3P spectral data are associated with one of the 12 groups (Fig. 3) by supervised classification using the minimum distance method. The whole spectral range of Band 3P is used to calculate the Euclidian distance between the normalized Band 3P spectral data and the supervised data. The Band 3P data are assigned to the group that has the minimum Euclidian distance. In general, the minimum distance is on the order of $10^{-5}$ or less. When Band $3 \mathrm{P}$

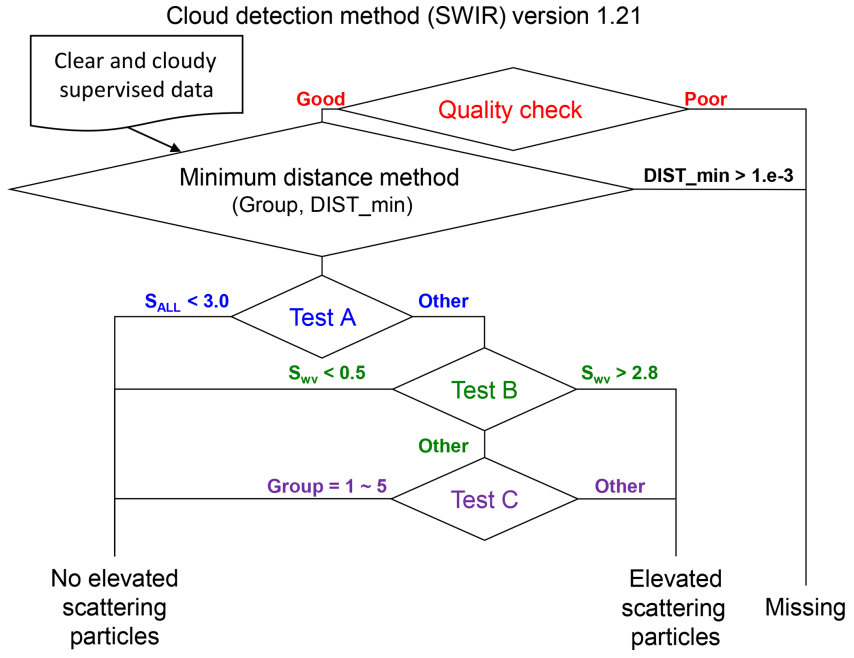

Figure 4. Flowchart of the method for detecting and classifying elevated scattering particles from SWIR spectra (Ver. 1.21). The terms in the flowchart are described in Table 1. 
spectral data are too noisy, the minimum distance value becomes large. Therefore, spectral data with minimum distance greater than $10^{-3}$ are also excluded as a low-quality spectrum and are not used for further analysis. These "poor/low quality data" were tagged as "missing" in the high-level cloud detection method. The spectral data with a "missing" flag $(0.5 \%-2.5 \%$ of the whole data) were not used for further analysis.

The measurement scenes (each set of TANSO-FTS observation sounding data) are categorized as "no elevated scattering particles" scenes or "elevated scattering particles" scenes based on the following three threshold tests.

The threshold tests use three parameters: $S_{\mathrm{wv}}, S_{\mathrm{ALL}}$, and Group (see also Table 1), shown in Fig. 4. The other parameters used to calculate $S_{\mathrm{wv}}$ and $S_{\mathrm{ALL}}$ are also listed in Table 1 . $S_{\mathrm{wv}}$ is the ratio between the averaged radiance of selected channels of Band 3P (see Fig. 2) and NOISE, and $S_{\mathrm{ALL}}$ is the ratio between the averaged radiance of the whole of Band $3 \mathrm{P}$ and NOISE.

In the first threshold step (Test A), the data with $S_{\mathrm{ALL}}$ less than 3.0 are sorted as "no elevated scattering particles", because the weak intensity in the water vapor saturated channels means there are definitely no clouds at upper levels.

At the second step (Test B), data with $S_{\mathrm{ALL}}$ greater than 3.0 are divided into two classes: "no elevated scattering particles" for $S_{\mathrm{wv}}$ less than 0.5 and "elevated scattering particles" for $S_{\mathrm{wv}}$ greater than 2.8. The values of the thresholds are derived from Fig. 5. Figure 5 shows the number of data, the score and accumulated score of $S_{\mathrm{wv}}$ for distances between TANSO-FTS and CALIOP up to $50 \mathrm{~km}$. Here, the score is the matching ratio with the CALIOP cloud flag. From Fig. 5b, a score of less than 0.1 corresponds to $S_{\mathrm{wv}}$ less than 0.5; i.e., approximately $90 \%$ of data with $S_{\mathrm{wv}}$ less than 0.5 have "no elevated scattering particles". On the other hand, from Fig. $5 \mathrm{c}$, an accumulated score larger than 0.8 corresponds to $S_{\mathrm{wv}}$ larger than 2.8 ; i.e., approximately $80 \%$ of the data with $S_{\mathrm{wv}}$ larger than 2.8 show "elevated scattering particles".

This method provides a cloud flag that indicates one of "no elevated scattering particles (clear; hereafter treated as 'clear' case for TANSO-FTS water vapor saturated band method)", "elevated scattering particles (cloud; hereafter treated as 'cloud' case for TANSO-FTS water vapor saturated band method)", or "missing" and also the 12 groups of spectral features. At the third (final) step, Test C sorts the data with the $S_{\mathrm{wv}}$ greater than 0.5 and less than 2.8 by the spectral shape group from 1 to 12 . As shown in the previous part, Groups 1-5 are sorted for "no elevated scattering particles (clear)" and Groups 6-12 are sorted as "elevated scattering particles (cloud)".

\section{Results}

This section describes a comparison with CALIOP during 2010. Figures mainly show data from January, April, July and October in 2010.

\subsection{Comparison with CALIOP}

The criteria for match-up between TANSO-FTS and CALIOP data were within $100 \mathrm{~km}$ for the distance between each footprint center location and within $5 \mathrm{~min}$ for the observation time difference. The cloud-top altitude at the highest layer (topmost of layer) and optical thickness from the CALIOP cloud layer product were used for the analysis. Note that because the TANSO-FTS detects the accumulated reflectance of cloud layers, the TANSO-FTS radiance is not always sensitive to the topmost cloud layers.

Figure 6 shows maps of the observation points of TANSOFTS that were matched with CALIOP observations within $100 \mathrm{~km}$ and the fraction of cloud flag, summarized monthly for January, April, July and October 2010. The matched points were concentrated within the northern mid-latitudes, approximately between 30 and $60^{\circ} \mathrm{N}$. In October, there are only a few match-up points due to the change of the nominal TANSO-FTS operation mode from five- to three-point mode. The clear and cloud fractions by TANSO-FTS water vapor saturated band method changed from month to month in the ranges $44 \%$ to $66 \%$ and $33 \%$ to $53 \%$, respectively. The clear fraction was larger than that of cloud except in April. The missing data ratio ranged from $1.0 \%$ to $6.2 \%$, and mainly resulted from the instability of the pointing mechanism (not shown).

Figure 7 shows histograms of the 12 spectral groups obtained by the minimum distance method (left column), and the CALIOP cloud-top altitude (middle column) and optical thickness (right column) for January, April, July and October 2010. The top (bottom) row shows clear (cloud) flag cases from the TANSO-FTS water vapor saturated band method.

For the clear case (top-left panels), most data were classified as Groups 1-5, but Group 7 also had a relatively large percentage (5\% to $10 \%)$ of the whole clear case except in July. The cloud-top altitudes were mainly distributed in the lower troposphere, especially over the ocean, and there were maxima of cloud-top altitude frequency over land at 3 and $10 \mathrm{~km}$. Optical thickness values were evenly distributed in the range 0.01 to 3.0 in the upper troposphere. In contrast, the optical thickness values above 3.0 were concentrated in the lower troposphere.

The numbers at the top of the left panels represent the matching ratio for TANSO-FTS data (clear or cloudy) against the CALIOP data. The two cases are given as a positive predictive value (i.e., TANSO-FTS and CALIOP clear case divided by all CALIOP (clear and cloud) data), which is the M1 case in Table 2, and a negative predictive value (TANSO-FTS and CALIOP cloud case divided by all 
(a) Number of $S_{W v}$ data points

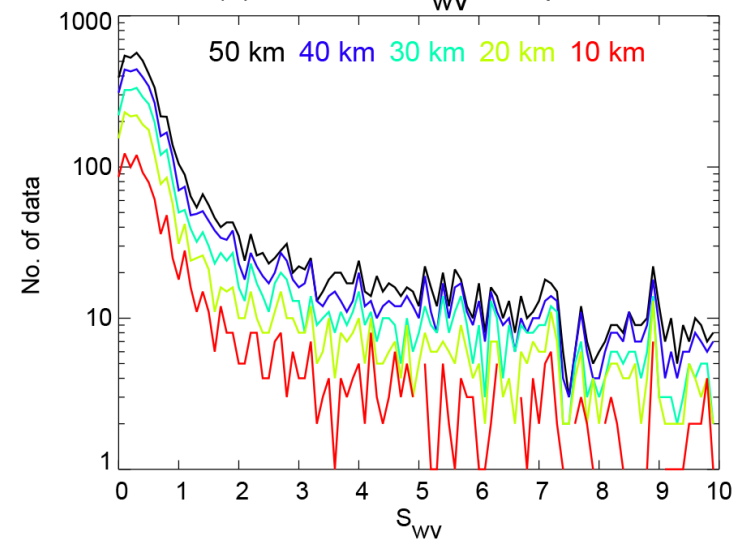

(b) Matching ratio of FTS with CALIOP

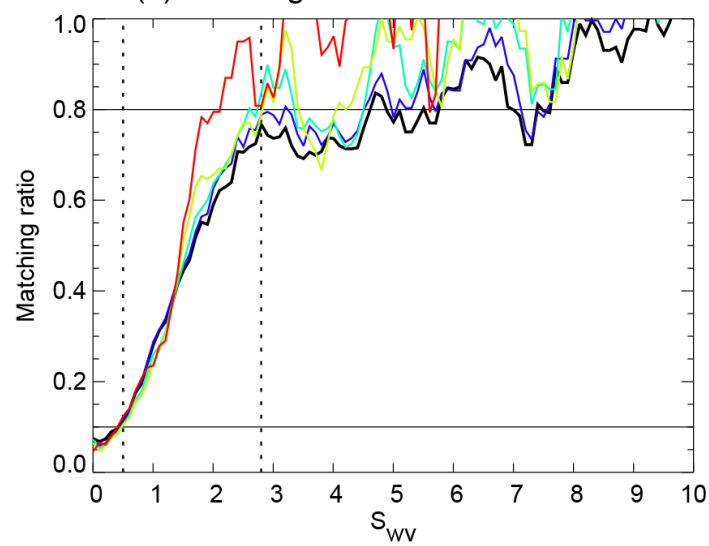

(c) Histogram of group wrt Swv

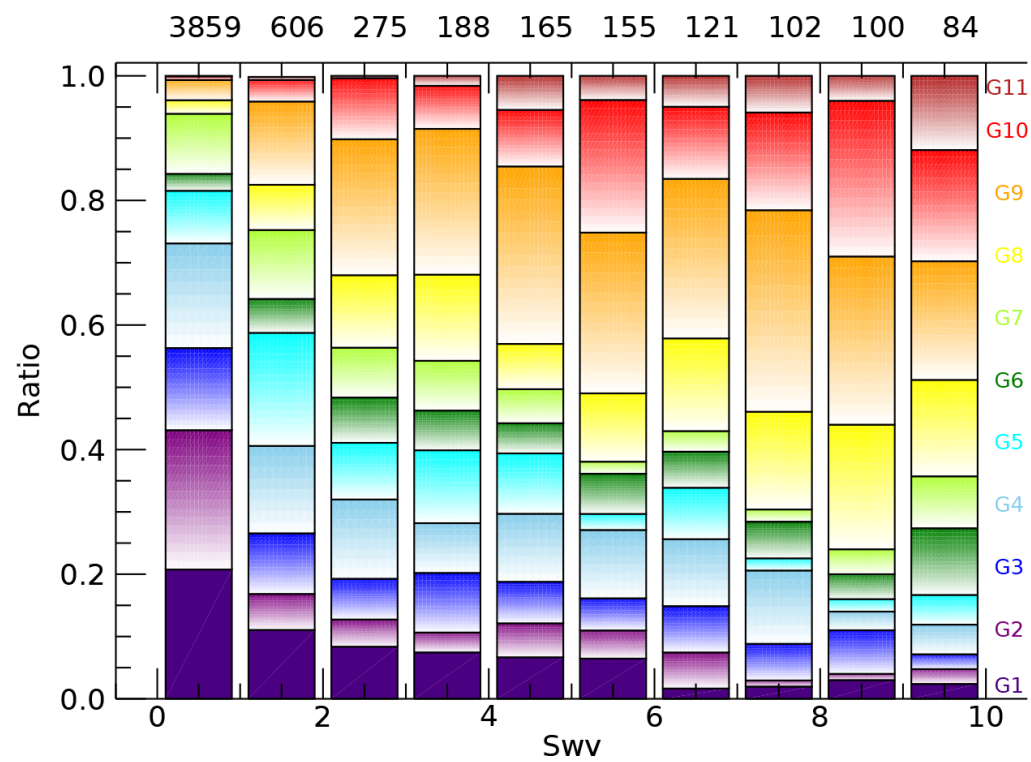

Figure 5. (a) Number of data points as a function of $S_{\mathrm{wv}}$ for distance between TANSO-FTS and CALIOP within 10, 20, 30, 40 and $50 \mathrm{~km}$. Panel (b) is the same as (a) but for the matching ratio between CALIOP cirrus clouds and TANSO-FTS cloud flag. (c) Histogram of group as a function of $S_{\mathrm{wv}}$ for distance between TANSO-FTS and CALIOP within $50 \mathrm{~km}$. The color bars indicate the group number from 1 to 12 . Group 12 is absent for $S_{\mathrm{wv}}$ less than 10.0. The numbers at the top of the graph are the total number in each bin of $S_{\mathrm{wv}}$. The analysis period is from 1 January to 31 December 2010.

Table 2. Definition of the matching ratio between the TANSO-FTS cloud flag and CALIOP.

\begin{tabular}{cc|cc}
\hline & & \multicolumn{2}{c}{ CALIOP } \\
& & clear & cloud \\
\hline TANSO-FTS & clear & $\mathrm{A}$ & $\mathrm{B}$ \\
& cloud & $\mathrm{C}$ & $\mathrm{D}$ \\
\hline $\mathrm{M} 1=\mathrm{A} /(\mathrm{A}+\mathrm{B}) \cdot 100$ & $\mathrm{M} 2=\mathrm{D} /(\mathrm{C}+\mathrm{D}) \cdot 100$ \\
$\mathrm{M} 3=(\mathrm{A}+\mathrm{D}) /(\mathrm{A}+\mathrm{B}+\mathrm{C}+\mathrm{D}) \cdot 100$
\end{tabular}

CALIOP - clear and cloud - data), which is the M2 case in Table 2 . The fraction shows that approximately $88 \%$ of the cloud cases determined by TANSO-FTS matched those from CALIOP. On the other hand, the matching ratio of the clear case was worse than that of the cloudy case, ranging from $47 \%$ to $51 \%$, because the cloud located in the lower troposphere could not be detected by TANSO-FTS.

Groups 7-12 dominated in the cloudy case (bottom rows). The most frequent cloud-top altitude was located around $10 \mathrm{~km}$, with the distribution falling off rapidly above $10 \mathrm{~km}$ and gradually below $10 \mathrm{~km}$. In April and July, the cloud-top altitude also had a peak in the lower troposphere (around $2 \mathrm{~km}$ ) over the ocean. The optical thickness in the upper tro- 
(a)
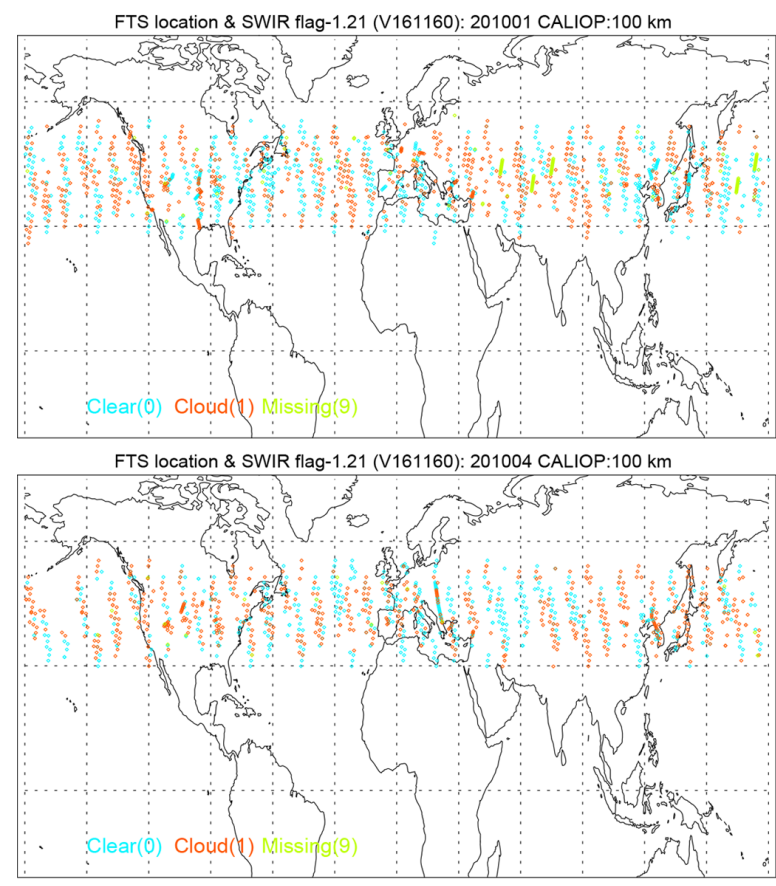

FTS location \& SWIR flag-1.21 (V161160): 201007 CALIOP:100 km

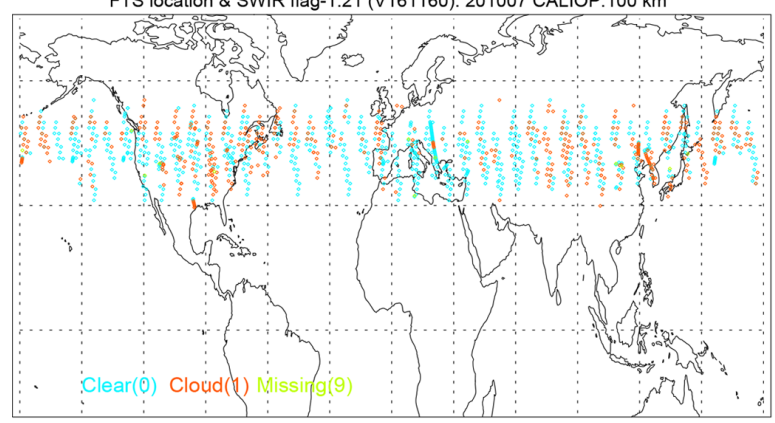

FTS location \& SWIR flag-1.21 (V161160): 201010 CALIOP:100 km

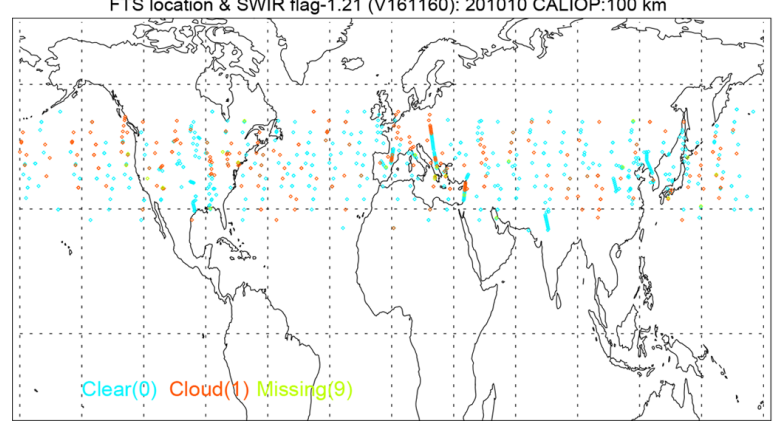

(b)
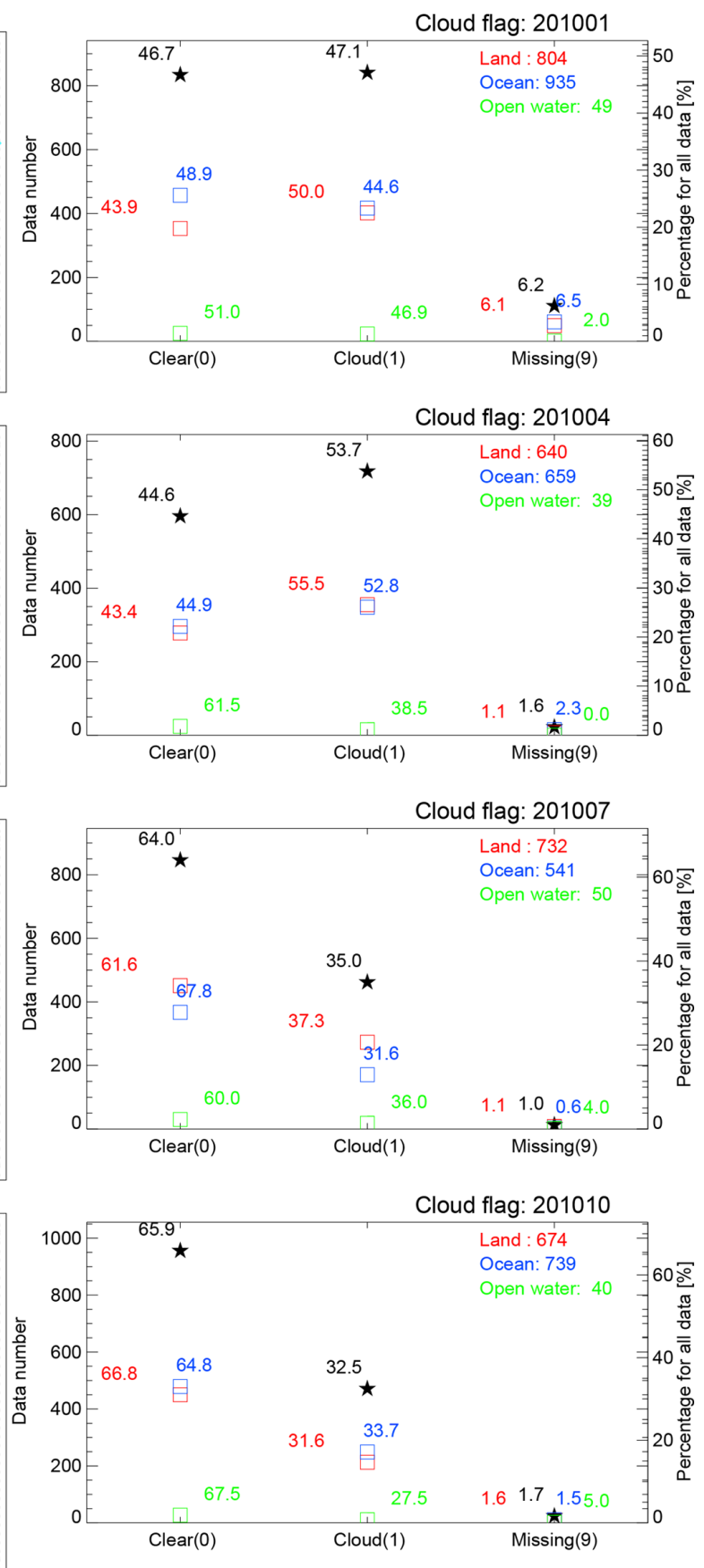

Figure 6. (a) Maps of match-up observation points for TANSO-FTS and CALIOP, colored according to the TANSO-FTS cloud flags: clear, cloud and missing are shown in light blue, orange and light green, respectively. (b) Among the data selected for comparing with CALIOP, the fraction of each cloud flag that has been derived from TANSO-FTS observations. The red, blue and green colors indicate observations over land, water and open water, respectively. The total data numbers in each case are given in the (b). The black star symbols indicate the data number and the percentage with respect to the total dataset is also shown. The open squares in red, blue and green show values over land, ocean and open water, respectively, and the values to the left or right of the square are the percentage of each cloud flag with respect to the total number of data. Results are shown (from top to bottom) for January, April, July and October 2010. 
(a)
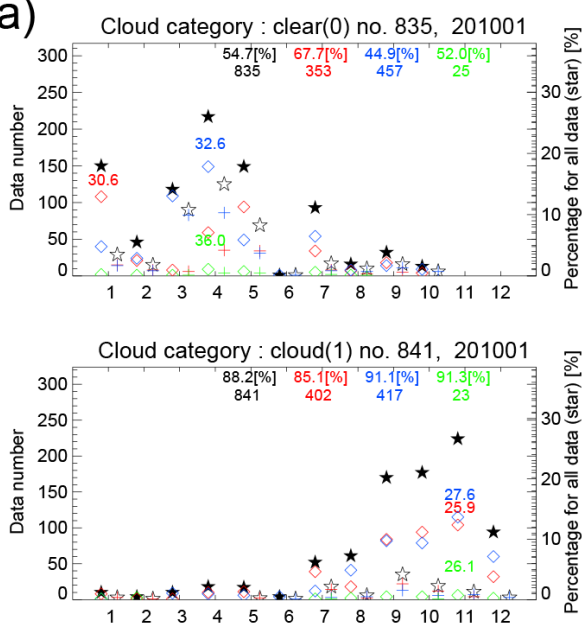

(b)
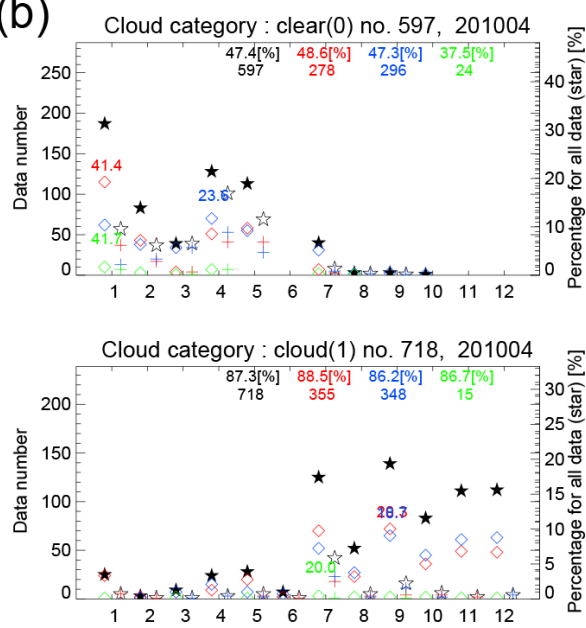
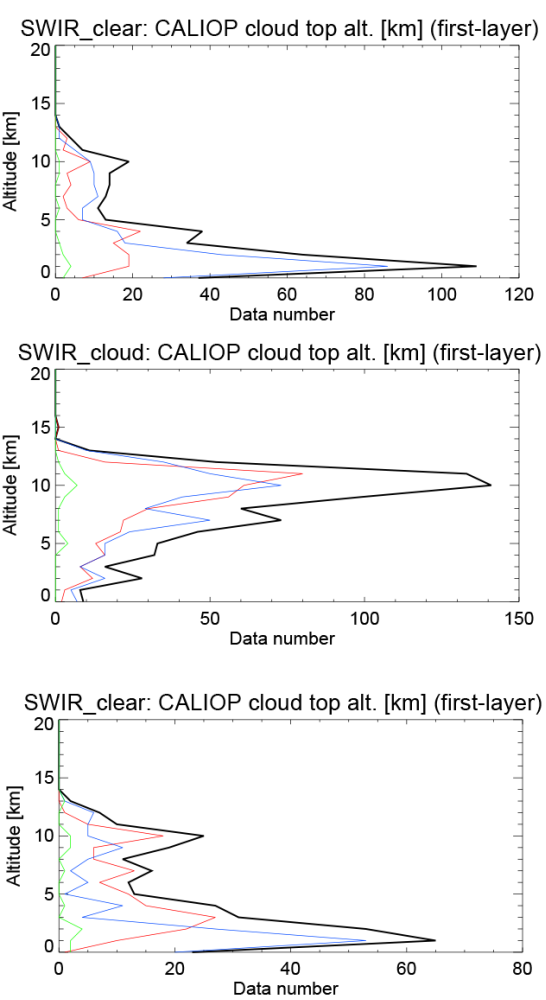

SWIR_cloud: CALIOP cloud top alt. [km] (first-layer)

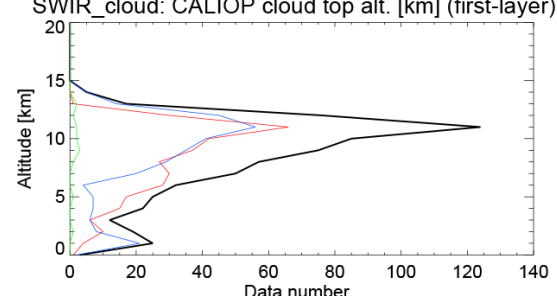

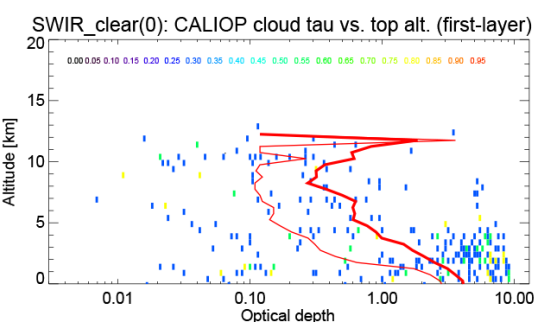
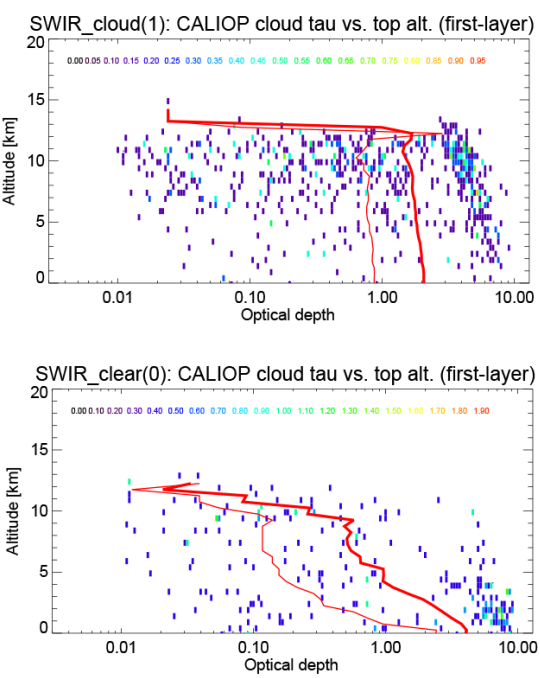

SWIR cloud(1): CALIOP cloud tau vs. top alt. (first-layer)

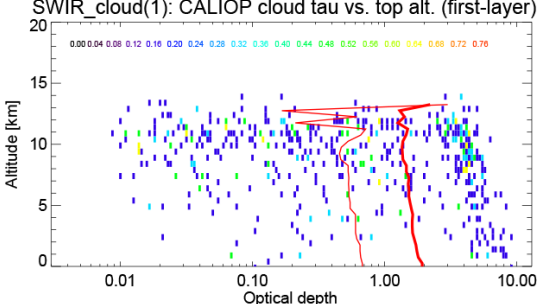

Figure 7.

posphere varied around 3.0; however, thinner optical thicknesses less than 0.1 were also similarly distributed.

Figure 8 shows the accuracy of TANSO-FTS relative to CALIOP. The matching ratio is M3, as defined in Table 2, i.e., the fraction of all the data that is cloud or clear in both datasets. At a distance of $25 \mathrm{~km}$, the matching ratio averaged for total cloud and over all of 2010 (black solid line) was approximately $71 \%$; the matching ratio over ocean was less than that over land for all distances and throughout the year, because the clouds in the lower troposphere could not be detected by the water vapor saturated method, as shown in Fig. 7. The poor matching ratio over the ocean during the boreal summer seems to be due to the total water vapor amount during summer which was approximately 3 times that in boreal winter (not shown). In addition, the poor matching ratio over the ocean was caused by the lower clouds which cover the northern Pacific during this season. The water vapor saturated method could not be detected in the lower clouds but the CALIOP could detect it. It is suggested that the water va- por amount may have an influence on the high-level cloud detection by the water vapor saturated method.

On the other hand, the matching ratio for cloud above $5 \mathrm{~km}$ cloud top altitude (dashed lines in Fig. 8) was approximately $86 \%$ at $25 \mathrm{~km}$ distance. The matching ratio decreased gradually with increasing distance between TANSO-FTS and CALIOP. The fraction above $5 \mathrm{~km}$ cloud top altitude is excellent because it removes the lower altitude clouds, especially over the ocean. The difference between cloud over land and ocean was not large and there was no clear seasonal dependency. It is suggested that the matching ratio was independent of both the seasonal variation of water vapor amount above $5 \mathrm{~km}$ altitude and the surface conditions.

\subsection{Case study for comparison with CALIOP}

Because TANSO-FTS observations have the advantage of a short revisit time (3-day cycle), the cloud variations associated with synoptic-scale phenomena can be captured. This 
(C)
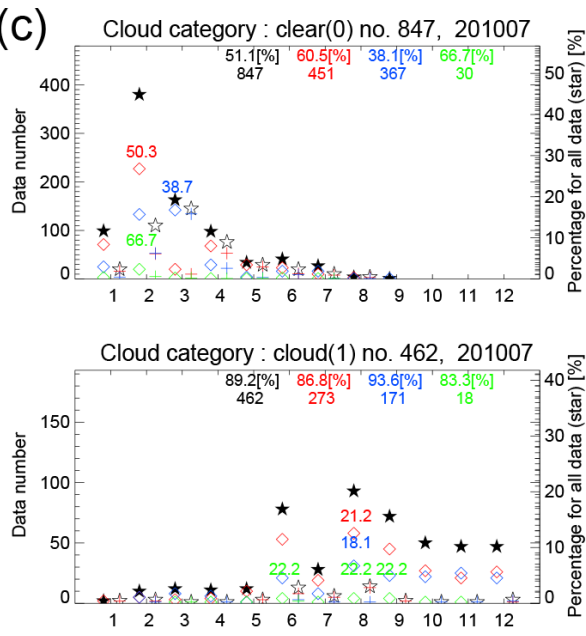

(d)
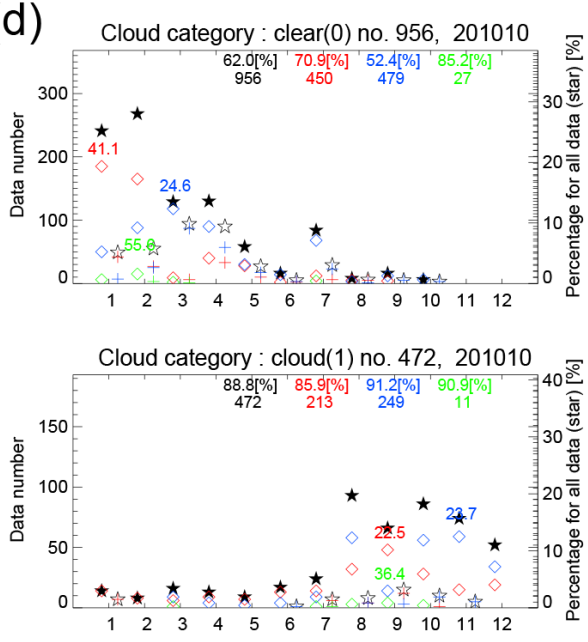

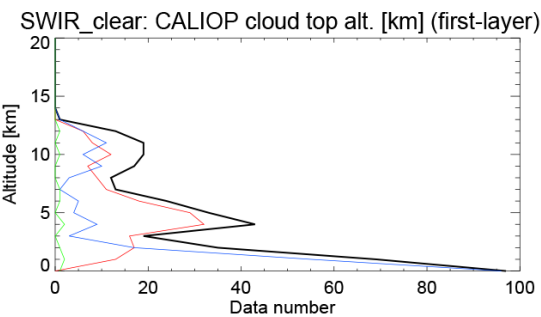

SWIR_cloud: CALIOP cloud top alt. [km] (first-layer)
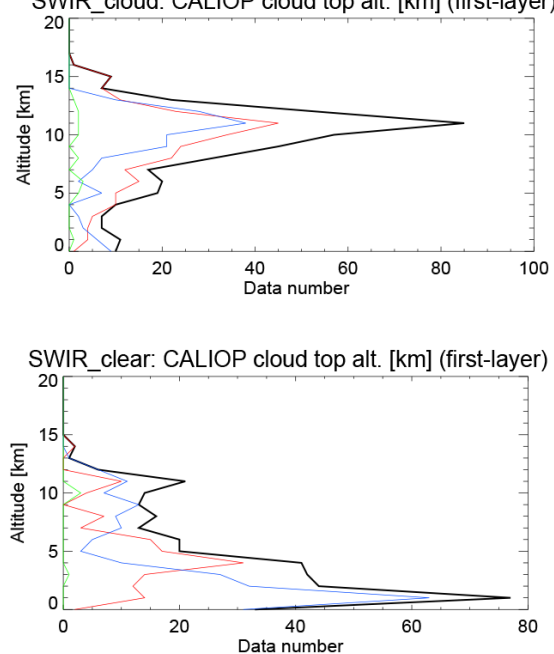

SWIR cloud: CALIOP cloud top alt. [km] (first-layer)

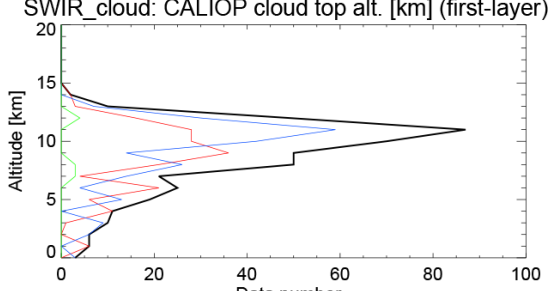

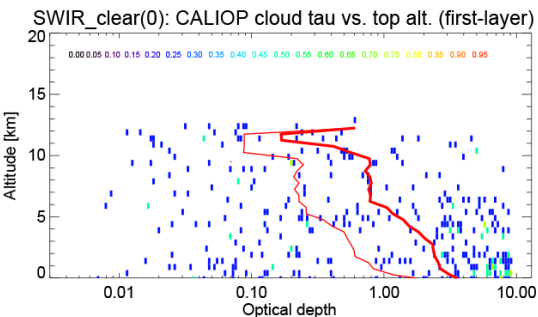

SWIR_cloud(1): CALIOP cloud tau vs. top alt. (first-layer)

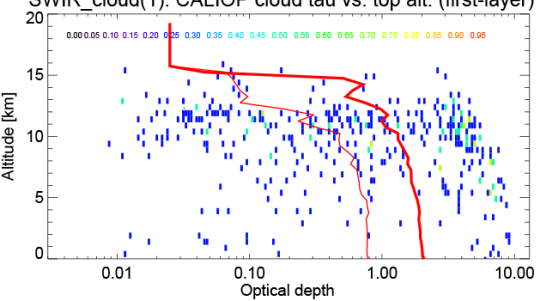

SWIR_clear(0): CALIOP cloud tau vs. top alt. (first-layer)
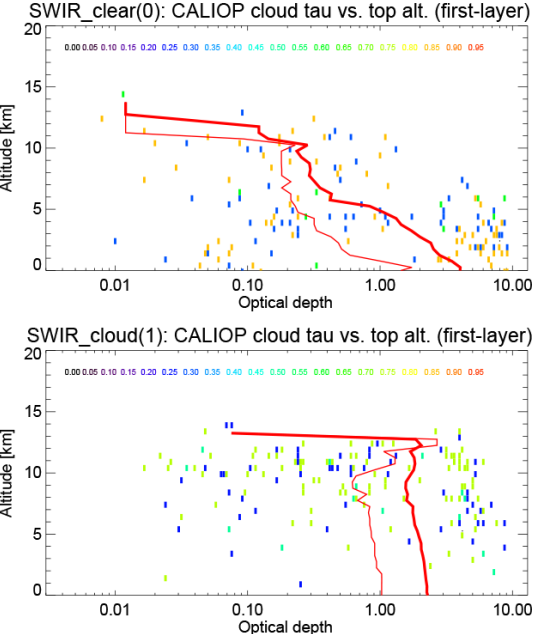

Figure 7. (a) The upper (lower) rows show the results for clear (cloud) flags from TANSO-FTS derived by the water vapor saturated method in January 2010. The left column is made up of histograms of the 12 spectral groups. The closed star indicates the whole dataset, and open diamonds indicate values over land (red), ocean (blue) and open water (green). The open star and cross (+) show the histogram for data that did not match CALIOP cloud flags. The values at the top of the panels show the matching ratio with CALIOP. The values near the red and blue diamonds show the highest percentage within land and ocean, respectively. The middle column represents the distribution of cloud top altitude from CALIOP. The black, red, blue and green lines show the whole dataset, land, ocean and open water, respectively. The distance between TANSO-FTS and CALIOP is $100 \mathrm{~km}$. The right-hand column represents the probability density distribution of the log-scale optical thickness from CALIOP as a function of altitude. The red thick (thin) line shows the average (median) of optical thickness at each altitude. The number at the top of the panels indicates the percentage of probability density. (b) Same as (a) but for April 2010. (c) Same as (a) but for July 2010. (d) Same as (a) but for October 2010.

subsection describes a case study for comparing the synoptic variation of cirrus cloud between TANSO-FTS and CALIOP.

A sudden stratospheric warming (SSW) event in the polar stratosphere induces upwelling in the tropical lower stratosphere. The upwelling causes adiabatic cooling of the lower stratosphere and the tropical tropopause layer (TTL), and as a result cirrus clouds in the TTL occur frequently during a SSW (Eguchi et al., 2007, 2015; Eguchi and Kodera, 2010). A SSW occurred around 25 January 2010, and cirrus cloud occurrence increased after that date (Kodera et al., 2015; Eguchi et al., 2015). Figure 9 shows the $2.5^{\circ}$ box-averaged cirrus occurrence 7 days before and after the key date ( 25 January), with increasing occurrence especially over the convective regions including South America, equatorial Africa, the maritime continent, and the western Pacific. The spatial distribution of cirrus fraction derived from the TANSO-FTS water vapor saturated band method was clearer than that from CALIOP due to higher temporal resolution (in other words, fewer missing grids at the $2.5^{\circ}$ grid size in the 7-day period), and the fraction from TANSO-FTS was approximately 1.75 times larger than that from CALIOP. The TANSO-FTS wa- 
(a) Annual mean in 2010

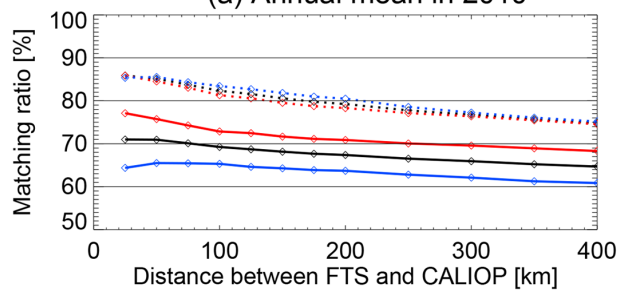

(b) Distance $25[\mathrm{~km}]$

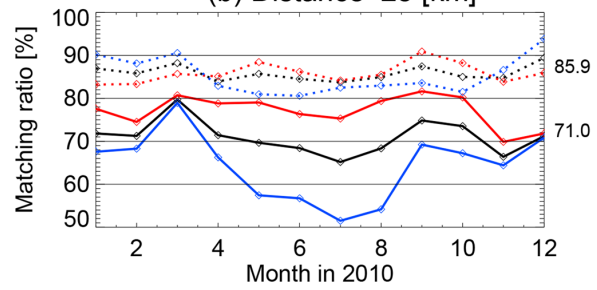

(d) Distance $200[\mathrm{~km}]$

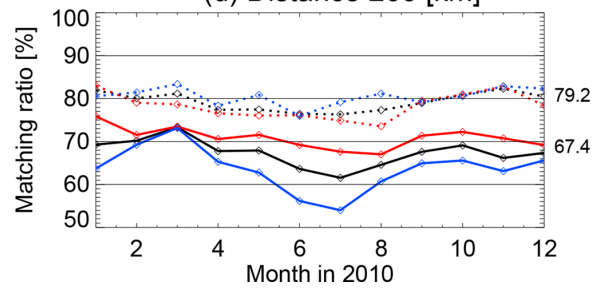

(c) Distance $100[\mathrm{~km}]$

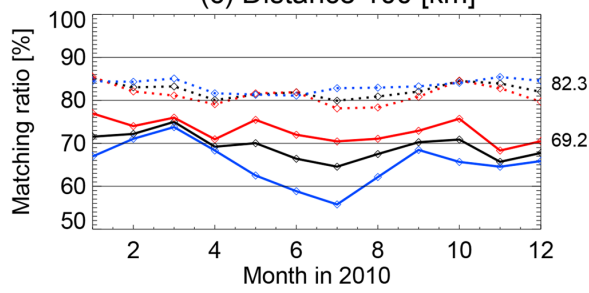

(e) Distance $400[\mathrm{~km}]$

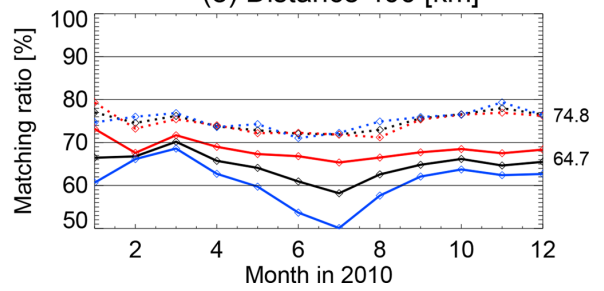

Figure 8. (a) Annual mean matching ratio in 2010 as a function of distance. The solid lines are the whole cloud data, and the dashed lines are for cloud that has cloud top altitude above $5 \mathrm{~km}$. The black, red, and blue lines indicate all data (over land, ocean and open water), data over land, and data over ocean, respectively. (b-e) Monthly matching ratio for distances between TANSO-FTS and CALIOP of 25, 100, 200, and $400 \mathrm{~km}$. The values on the right-hand side of each panel show the annual mean.

ter vapor saturated band method could be useful for studying cirrus cloud features over a short period.

\section{Summary and conclusions}

The main purpose of GOSAT is the observation of greenhouse gases, especially $\mathrm{XCO}_{2}$ and $\mathrm{XCH}_{4}$. The published standard product provides these trace gases only over cloudfree locations that are defined mainly by the TANSO-CAI cloud flag and a simplified cloud flag using the water vapor saturated band to avoid contamination due to clouds. Cloud information from the same instrument is useful for detecting the influence of cloud and retrieving the trace gases more accurately. However, the TANSO-CAI cloud flag cannot detect all cloud, and struggles with thinner cirrus cloud in particular, and the current operational cloud flag derived from the water vapor saturated band of the TANSO-FTS covers the high-level clouds.

Previous studies have used the water vapor saturated band to detect cirrus clouds in the upper troposphere (Gao et al., 1993, 2002, 2004). The current water vapor saturated method was roughly defined by the noise level in the water vapor saturated band $\left(5150-5200 \mathrm{~cm}^{-1}\right)$. The GOSAT TANSO-FTS has a higher spectral resolution $\left(0.27 \mathrm{~cm}^{-1}\right)$ than other satellite instruments, so a more precise detection method can be developed. The present study utilized the typical spectral shape of Band 3P constructed by the cluster analysis.

We used the 12 groups (5 clear and 7 cloudy cases) of the spectral shape of Band 3P derived from the cluster analysis together with spectral features, such as the SNR and the Euclidian distance of cluster analysis, to detect elevated particles such as cirrus clouds located in the upper troposphere. Each TANSO-FTS scene is classified into one of three categories: "no elevated scattering particles", "elevated scattering particles" and "missing". The "missing" category mainly results from instability of the pointing mechanism.

GOSAT TANSO-FTS data matched with the CALIOP footprint within $100 \mathrm{~km}$ and $5 \mathrm{~min}$ were distributed mainly over latitudes between 30 and $60^{\circ} \mathrm{N}$ (Fig. 6). A comparison with CALIOP revealed that the clear and cloud categories had almost the same fraction in boreal winter, the matching ratio of clear was larger than that of cloudy in the summer and autumn and the ratio of cloudy was larger than that of clear in spring. Since there is more water vapor in boreal summer than in other seasons, the matching ratio, especially over the ocean, was worse. However, no clear sea- 
(a) TANSO-FTS cirrus fraction [\%] , 18-24 Jan 2010

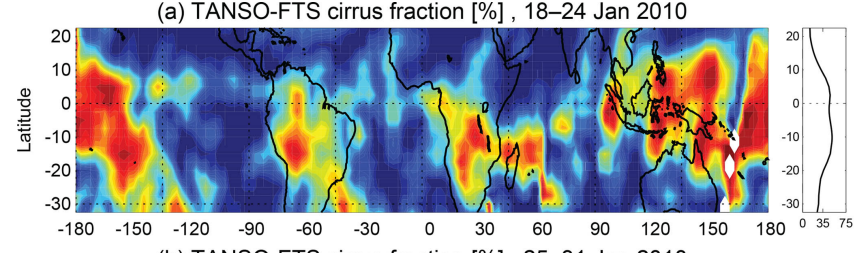

(b) TANSO-FTS cirrus fraction [\%] , 25-31 Jan 2010

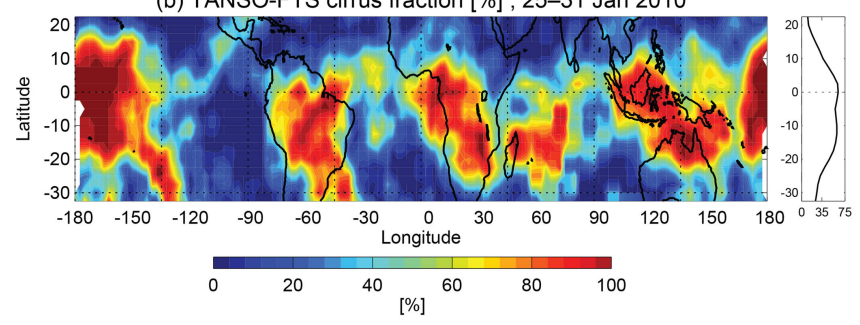

(c) CALIOP cirrus fraction [\%] day and night, 18-24 Jan 2010

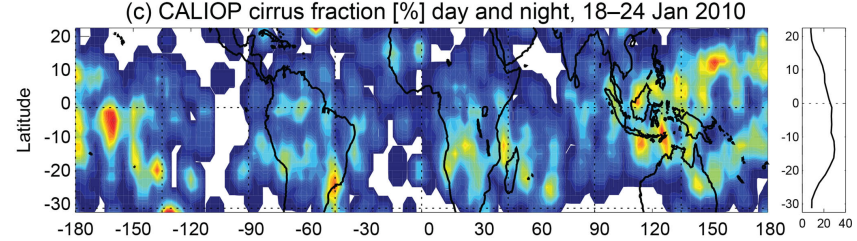

(d) CALIOP cirrus fraction [\%] day and night, 25-31 Jan 2010

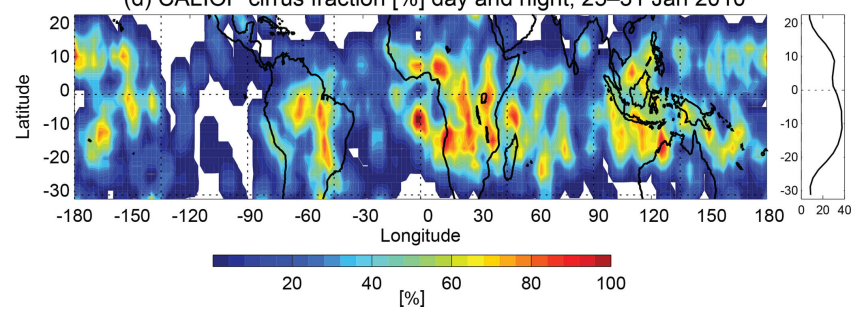

Figure 9. Maps of cirrus cloud occurrence frequency from the TANSO-FTS water vapor saturated method and CALIOP plotted for $2.5^{\circ}$ boxes. (a, c) On 18 and 24 January and on (b, d) 25 and 31 January. Both datasets were smoothed using 3-grid box smoothing. Panels to the right of the maps show the zonal mean fraction.

sonal variation was found in the matching ratio for data that had a CALIOP cloud-top altitude above $5 \mathrm{~km}$ (Fig. 8). It is suggested that the water vapor saturated band method is not correlated with water vapor amount above $5 \mathrm{~km}$ in the midlatitudes. In the tropics, the water vapor amount decreases rapidly above $8 \mathrm{~km}$; consequently, this method will detect cloud with a cloud-top altitude above this level in the tropics.

A comparison with CALIOP cloud data gave an approximately $86 \%$ matching ratio for elevated particles detected by TANSO-FTS, as shown in Figs. 7 and 8 . The method can detect elevated particles (cirrus clouds) located in the upper troposphere with very thin optical thickness, such as 0.1 or less. For reference, the matching ratio D / $(B+D)$ as defined in Table 2 as the function of CALIOP optical thickness shows $40 \%-80 \%$ at optical thickness below 5.0 (not shown). It shows that the new method from this study has good potential for measuring cirrus clouds with various op- tical thicknesses. The present method detects thinner cirrus clouds with a similar capability as the current method of the GOSAT product; however, the middle layer clouds of around $5 \mathrm{~km}$ cloud top altitude can be detected better by the current method as shown in Fig. 10.

The water vapor saturated band method can capture the variations in cirrus cloud on the synoptic scale in more detail than those derived from CALIOP, which observes cloud and aerosol with a 16-day revisit orbit (Fig. 9). The cirrus cloud dataset derived from TANSO-FTS can be a useful additional dataset for studying cirrus clouds on synoptic to interannual temporal scales. The GOSAT data are available from April 2009 to the present; we have already accumulated data for a period exceeding 9 years.

Finally, the thinner clouds, especially cirrus clouds, affect the retrieval of trace gases and are a major error source. This method should allow GOSAT to produce retrievals of greenhouse gases under thinner cloud conditions. As for the results, the thinner cloud effect might contaminate the retrieved greenhouse gas amount. The issue is beyond the scope of the present study, which will be done as future work.

Another satellite that targets greenhouse gases also has the same contamination with thinner clouds: the Orbiting Carbon Observatory-2 (OCO-2) project reported that the $\mathrm{XCO}_{2}$ retrieval amount was improved by removing cirrus cloud contamination (David Crisp, personal communication, 2017). Work in the near future aims to quantitatively investigate the effect of cirrus contamination on retrieved greenhouse gases and to improve the retrieved values.

Data availability. The TANSO-FTS data are available via the GOSAT Data Archive Service (GDAS) at https://data2.gosat.nies. go.jp/ (GDAS, 2017). The CALIOP dataset is available at https: //eosweb.larc.nasa.gov/project/calipso/calipso_table/ (NASA Langley Research Center Atmospheric Science Data Center, 2018; Vaughan et al., 2018).

Author contributions. NE designed the present study, analyzed the data and prepared the manuscript. YY developed the cirrus cloud detecting method and provided the cirrus cloud flag.

Competing interests. The authors declare that they have no conflict of interest.

Acknowledgements. This study was performed within the framework of the GOSAT research announcement.

Edited by: Piet Stammes

Reviewed by: three anonymous referees 
(a) Present_Clear/Current_Clear: CALIOP cloud top alt. [km]
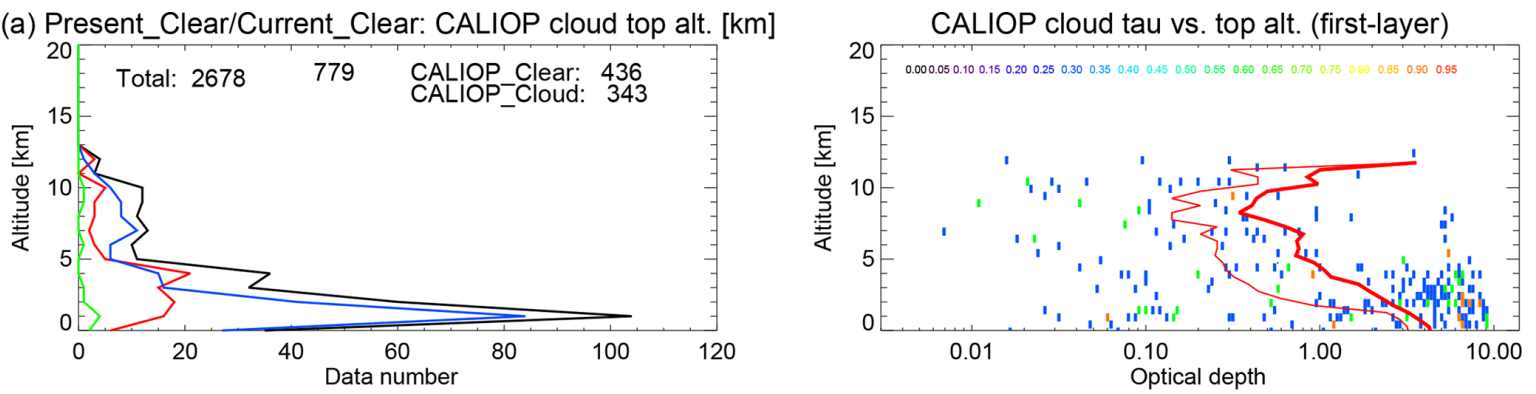

(b) Present_Clear/Current_Cloud: CALIOP cloud top alt. [km]
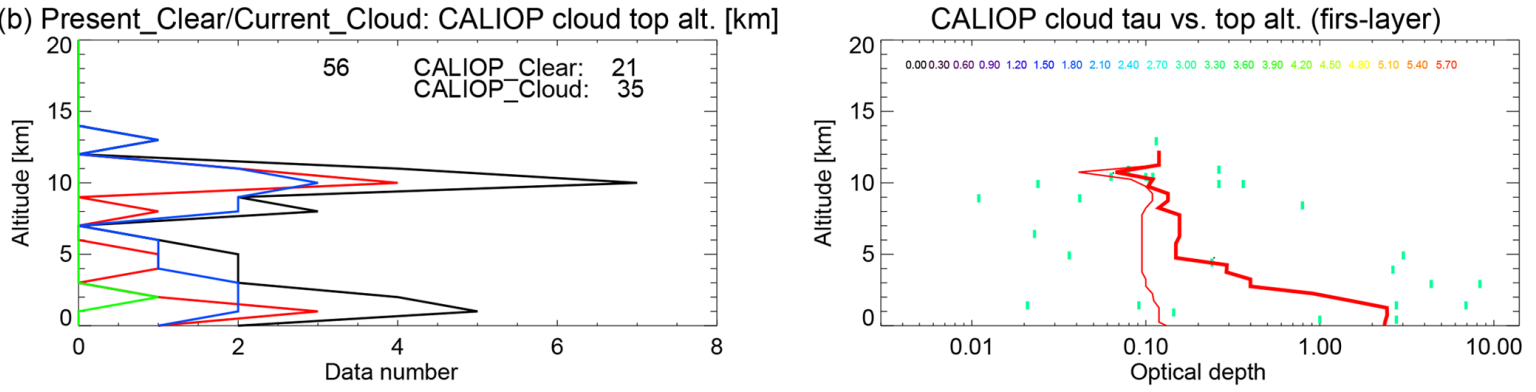

(c) Present_Cloud/Current_Clear: CALIOP cloud top alt. [km]
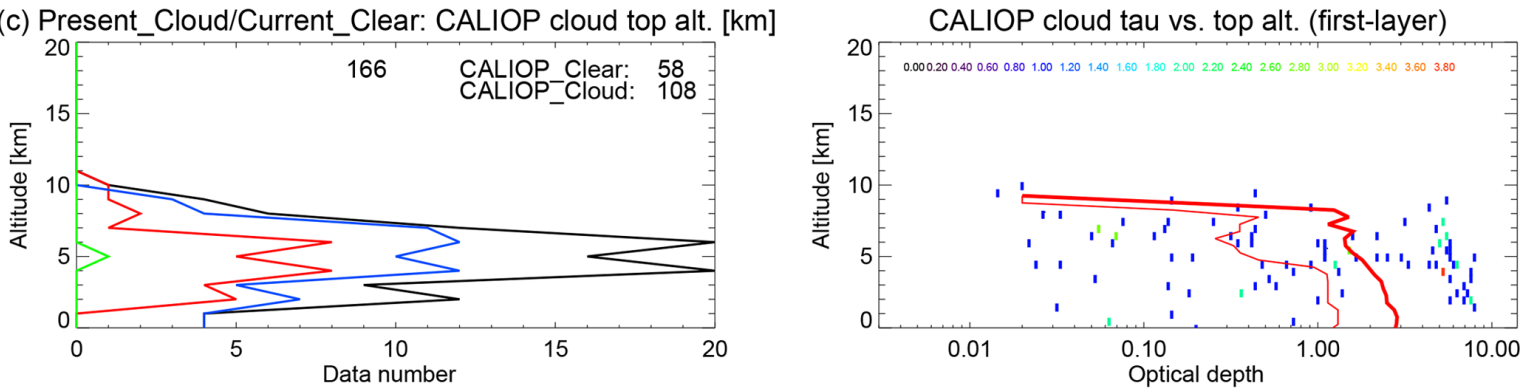

(d) Present_Cloud/Current_Cloud: CALIOP cloud top alt. [km]
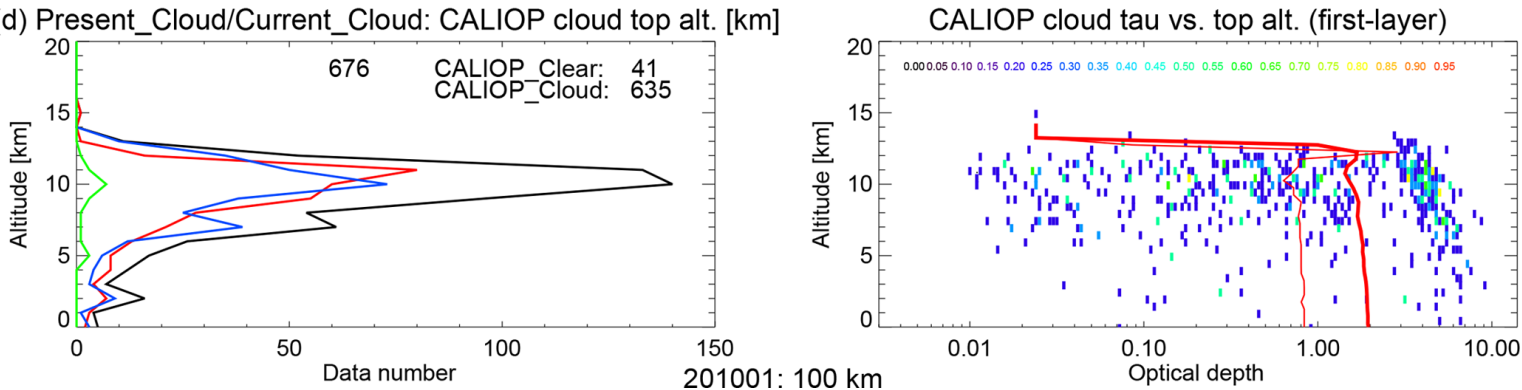

Figure 10. Same as the middle and right columns of Fig. 7 but for the clear and cloud cases defined by the present and current water vapor saturated methods. The distance between TANSO-FTS and CALIOP is $100 \mathrm{~km}$ and the period is January 2010.

\section{References}

Clough, S. A., Shephard, M. W., Mlawer, E. J., Delamere, J. S., Iacono, M. J., Cady-Pereira, K., Boukabara, S., and Brown, P. D.: Atmospheric radiative transfer modeling: a summary of the AER codes, J. Quant. Spectrosc. Ra., 91, 233-244, 2005.

Dessler, A. E. and Yang, P.: The Distribution of Tropical Thin Cirrus Clouds Inferred from Terra MODIS Data, J. Climate, 16, 1241-1247, https://doi.org/10.1175/15200442(2003)16<1241:TDOTTC>2.0.CO;2, 2003.

Eguchi, N. and Kodera, K.: Impacts of Stratospheric Sudden Warming Event on Tropical Clouds and Moisture
Fields in the TTL: A Case Study, SOLA, 6, 137-140, https://doi.org/10.2151/sola.2010-035, 2010.

Eguchi, N., Yokota, T., and Inoue, G.: Characteristics of cirrus clouds from ICESat/GLAS observations, Geophys. Res. Lett., 34, L09810, https://doi.org/10.1029/2007GL029529, 2007.

Eguchi, N., Kodera, K., and Nasuno, T.: A global non-hydrostatic model study of a downward coupling through the tropical tropopause layer during a stratospheric sudden warming, Atmos. Chem. Phys., 15, 297-304, https://doi.org/10.5194/acp-15-2972015, 2015.

Gao, B.-C., Goetz, A. F. H., and Wiscombe, W. J.: Cirrus cloud detection from Airborne Imaging Spectrometer Data using the 
$1.38 \mu \mathrm{m}$ water vapor band, Geophys. Res. Lett., 20, 301-304, https://doi.org/10.1029/93GL00106, 1993.

Gao, B.-C., Kaufman, Y. J., Han, W., and Wiscombe, W. J.: Correction of Thin Cirrus Path Radiance in the 0.4$1.0 \mu \mathrm{m}$ Spectral Region Using the Sensitive 1.375- $\mu \mathrm{m}$ Cirrus Detecting Channel, J. Geophys. Res., 103, 32169-32176, https://doi.org/10.1029/98JD02006, 1998.

Gao, B.-C., Yang, P., Han, W., Li, R. R., and Wiscombe, W. J.: An Algorithm Using Visible and 1.38- $\mu \mathrm{m}$ Channels to Retrieve Cirrus Cloud Reflectances From Aircraft and Satellite Data, IEEE T. Geosci. Remote Sens., 40, 1659-1668, https://doi.org/10.1109/TGRS.2002.802454, 2002.

Gao, B.-C., Montes, M. J., and Davis, C. O.: Refinement of Wavelength Calibrations of Hyperspectral Imaging Data Using a Spectrum-Matching Technique, Remote Sens. Environ., 90, 424433, https://doi.org/10.1016/j.rse.2003.09.002, 2004.

GOSAT Data Archive Service (GDAS): The GOSAT TANSOFTS Level 1B data, https://data2.gosat.nies.go.jp/index_en.html, GOSAT Level 1 Product Description Document TANSOFTS Section, P.93 Japan Aerospace Exprolation Agency, MAS130014, https://data2.gosat.nies.go.jp/doc/document.html\# Document, last access: 19 August 2017.

Guerlet, S., Butz, A., Schepers, D., Basu, S., Hasekamp, O. P., Kuze, A., Yokota, T., Blavier, J.-F., Deutscher, N. M., Griffith, D. W. T., Hase, F., Kyro, E., Morino, I., Sherlock, V., Sussmann, R., Galli, A., and Aben, I.: Impact of aerosol and thin cirrus on retrieving and validating $\mathrm{XCO}_{2}$ from GOSAT shortwave infrared measurements, J. Geophys. Res., 118, 4887-4905, https://doi.org/10.1002/jgrd.50332, 2013.

Hutchison, K. D., Iisager, B. D., and Hauss, B.: The use of global synthetic data for pre-launch tuning of the VIIRS Cloud Mask algorithm, Int. J. Remote Sens., 33, 1400-1423, https://doi.org/10.1080/01431161.2011.571299, 2012.

Holz, R. E., Platnick, S., Holz, R. E., Platnick, S., Meyer, K., Vaughan, M., Heidinger, A., Yang, P., Wind, G., Dutcher, S., Ackerman, S., Amarasinghe, N., Nagle, F., and Wang, C.: Resolving ice cloud optical thickness biases between CALIOP and MODIS using infrared retrievals, Atmos. Chem. Phys., 16, 50755090, https://doi.org/10.5194/acp-16-5075-2016, 2016.

Ishida, H., Nakajima, T. Y., Yokota, T., Kikuchi, N., and Watanabe, H.: Investigation of GOSAT TANSOCAI Cloud Screening Ability through an Intersatellite Comparison, J. Appl. Meteorol. Clim., 50, 1571-1586, https://doi.org/10.1175/2011JAMC2672.1, 2011.

Kodera, K., Funatsu, B. M., Claud, C., and Eguchi, N.: The role of convective overshooting clouds in tropical stratospheretroposphere dynamical coupling, Atmos. Chem. Phys., 15, 67676774, https://doi.org/10.5194/acp-15-6767-2015, 2015.

Kuze, A., Suto, H., Nakajima, M., and Hamazaki, T.: Thermal and near infrared sensor for carbon observation Fourier-transform spectrometer on the Greenhouse Gases Observing Satellite for greenhouse gases monitoring, Appl. Optics, 48, 6716-6733, https://doi.org/10.1364/AO.48.006716, 2009.

Kuze, A., Suto, H., Shiomi, K., Urabe, T., Nakajima, M., Yoshida, J., Kawashima, T., Yamamoto, Y., Kataoka, F., and Buijs, H.: Level 1 algorithms for TANSO on GOSAT: processing and on-orbit calibrations, Atmos. Meas. Tech., 5, 2447-2467, https://doi.org/10.5194/amt-5-2447-2012, 2012.
Kuze, A., Suto, H., Shiomi, K., Kawakami, S., Tanaka, M., Ueda, Y., Deguchi, A., Yoshida, J., Yamamoto, Y., Kataoka, F., Taylor, T. E., and Buijs, H. L.: Update on GOSAT TANSOFTS performance, operations, and data products after more than 6 years in space, Atmos. Meas. Tech., 9, 2445-2461, https://doi.org/10.5194/amt-9-2445-2016, 2016.

MacQueen, B. J.: On the Asymptotic Behavior of k-means, Defense Technical Information Center, 1965.

McGill, J. B., Etienne, R. S., Gray, J. S., Alonso, D., Anderson, M. J., Benecha, H. K., Dornelas, M., Enquist, B. J., Green, J. L., He, F., Hurlbert, A. H., Magurran, A. E., Marquet, P. A., Maurer, B. A, Ostling, A., Soykan, C. Y., Ugland, K. I., and Whit, E. P.: Species abundance distributions: moving beyond single prediction theories to integration within an ecological framework, Ecol. Lett., 10, 995-1015, https://doi.org/10.1111/j.14610248.2007.01094.x, 2007.

Nakajima, T. and Tanaka, M.: Matrix formulations for the radiative transfer of solar radiation in a plane-parallel scattering atmosphere, J. Quant. Spectrosc. Ra., 35, 13-21, 1986.

NASA Langley Research Center Atmospheric Science Data Center: The CALIPSO level $25 \mathrm{~km}$ cloud layer product, https://eosweb.larc.nasa.gov/project/calipso/cal_lid_12_ 05kmclay-standard-v4-10, last access: 19 February 2018.

Nazaryan, H., McCormick, M. P., and Menze, M. P.: Global characterization of cirrus clouds using CALIPSO data, J. Geophys. Res., 113, D16211, https://doi.org/10.1029/2007JD009481, 2008.

Sassen, K., Wang, Z., and Liu, D.: Global distribution of cirrus clouds from CloudSat/Cloud-Aerosol Lidar and Infrared Pathfinder Satellite Observations (CALIPSO) measurements, J. Geophys. Res., 113, D00A12, https://doi.org/10.1029/2008JD009972, 2008.

Someya, Y., Imasu, R., Saitoh, N., Ota, Y., and Shiomi, K.: A development of cloud top height retrieval using thermal infrared spectra observed with GOSAT and comparison with CALIPSO data, Atmos. Meas. Tech., 9, 1981-1992, https://doi.org/10.5194/amt9-1981-2016, 2016.

Vaughan, M., Pitts, M., Trepte, C., Winker, D., Detweiler, P., Garnier, A., Getzewich, B., Hunt, W., Lambeth, J., Lee, K.-P., Lucker, P., Murray, T., Rodier, S., Tremas, T., Bazureau, A., and Pelon, J.: Cloud-Aerosol LIDAR Infrared Pathfinder Satellite Observations (CALIPSO) data management system data products catalog, Release 4.10, NASA Langley Research Center Document PC-SCI-503, 185 pp., available at: https://www-calipso. larc.nasa.gov/products/CALIPSO_DPC_Rev4x10.pdf, last access: 31 August 2018.

Winker, D. M., Hunt, W. H., and McGill, M. J.: Initial performance assessment of CALIOP, Geophys. Res. Lett., 34, L19803, https://doi.org/10.1029/2007GL030135, 2007.

Winker, D. M., Pelon, J., Coakley Jr., J. A., Ackerman, S. A., Charlson, R. J., Colarco, P. R., Flamant, P., Fu, Q., Hoff, R. M., Kittaka, C., Kubar, T. L., Le Treut, H., Mccormick, M. P., Mégie, G., Poole, L., Powell, K., Trepte, C., Vaughan, M. A., and Wielicki, B. A.: The CALIPSO Mission : A Global 3D View of Aerosols and Clouds, Bulletin of the American Meteorological Society, 91, 1211-1229, https://doi.org/10.1175/2010BAMS3009.1, 2010.

Yoshida, Y., Ota, Y., Eguchi, N., Kikuchi, N., Nobuta, K., Tran, H., Morino, I., and Yokota, T.: Retrieval algorithm for $\mathrm{CO}_{2}$ and 
$\mathrm{CH}_{4}$ column abundances from short-wavelength infrared spectral observations by the Greenhouse gases observing satellite, Atmos. Meas. Tech., 4, 717-734, https://doi.org/10.5194/amt-4717-2011, 2011. 